\title{
Adverse Event Dictionary
}

National Cancer Institute

\section{Source}

National Cancer Institute. Adverse Event Dictionary. NCI Thesaurus. Code C49700.

A reference source that provides meanings of words related to adverse events. 